University of Nebraska - Lincoln

DigitalCommons@University of Nebraska - Lincoln

2-15-2018

\title{
Gamma irradiation inactivates honey bee fungal, microsporidian, and viral pathogens and parasites
}

Michael Simone-Finstrom

Kate Aronstein

Michael Goblirsch

Frank Rinkevich

Lilia de Guzman

Follow this and additional works at: https://digitalcommons.unl.edu/usdaarsfacpub

This Article is brought to you for free and open access by the U.S. Department of Agriculture: Agricultural Research Service, Lincoln, Nebraska at DigitalCommons@University of Nebraska - Lincoln. It has been accepted for inclusion in Publications from USDA-ARS / UNL Faculty by an authorized administrator of DigitalCommons@University of Nebraska - Lincoln. 


\title{
Gamma irradiation inactivates honey bee fungal, microsporidian, and viral pathogens and parasites
}

\author{
Michael Simone-Finstrom ${ }^{\mathrm{a}, *}$, Kate Aronstein ${ }^{\mathrm{a}}$, Michael Goblirsch ${ }^{\mathrm{b}}$, Frank Rinkevich ${ }^{\mathrm{a}}$, \\ Lilia de Guzman ${ }^{\mathrm{a}}$ \\ a USDA-ARS, Honey Bee Breeding, Genetics and Physiology Laboratory, Baton Rouge, LA 70820, USA \\ ${ }^{\mathrm{b}}$ Department of Entomology, University of Minnesota, Twin Cities, USA
}

\section{A R T I C L E I N F O}

\section{Keywords:}

Apis mellifera

Gamma irradiation

Deformed wing virus

Chalkbrood

Pathogen inactivation

Honey bee health

\begin{abstract}
A B S T R A C T
Managed honey bee (Apis mellifera) populations are currently facing unsustainable losses due to a variety of factors. Colonies are challenged with brood pathogens, such as the fungal agent of chalkbrood disease, the microsporidian gut parasite Nosema spp., and several viruses. These pathogens may be transmitted horizontally from worker to worker, vertically from queen to egg and via vectors like the parasitic mite, Varroa destructor. Despite the fact that these pathogens are widespread and often harbored in wax comb that is reused from year to year and transferred across beekeeping operations, few, if any, universal treatments exist for their control. In order to mitigate some of these biological threats to honey bees and to allow for more sustainable reuse of equipment, investigations into techniques for the sterilization of hive equipment and comb are of particular significance. Here, we investigated the potential of gamma irradiation for inactivation of the fungal pathogen Ascosphaera apis, the microsporidian Nosema ceranae and three honey bee viruses (Deformed wing virus [DWV], Black queen cell virus [BQCV], and Chronic bee paralysis virus [CBPV]), focusing on the infectivity of these pathogens post-irradiation. Results indicate that gamma irradiation can effectively inactivate A. apis, N. ceranae, and DWV. Partial inactivation was noted for BQCV and CBPV, but this did not reduce effects on mortality at the tested, relatively high doses. These findings highlight the importance of studying infection rate and symptom development post-treatment and not simply rate or quantity detected. These findings suggest that gamma irradiation may function as a broad treatment to help mitigate colony losses and the spread of pathogens through the exchange of comb across colonies, but raises the question why some viruses appear to be unaffected. These results provide the basis for subsequent studies on benefits of irradiation of used comb for colony health and productivity.
\end{abstract}

\section{Introduction}

In recent years, honey bee populations have been under a near constant threat of various pathogens, parasites, pests and anthropogenic stressors (Cox-Foster et al., 2007; vanEngelsdorp and Meixner, 2010). While treatments currently exist for some of these pathogens and parasites, there is the continual risk of the development of resistance to chemical treatments and contamination of hive products. For example, the causative bacterial agent of the larval disease American foulbrood (AFB; Paenibacillus larvae) exhibits widespread resistance to antibiotic treatment (Evans, 2003) and treatment residues persist in honey, which is a human health concern (reviewed in Genersch (2010)). In addition, currently registered antibiotic treatments for some pathogens are only moderately effective (Williams et al., 2008) or can possibly make the infection worse, as seen in the case of the microsporidian gut parasite

\section{Nosema ceranae (Huang et al., 2013).}

Complicating the fact that reliable and safe treatments do not currently exist for the treatment of many honey bee diseases, is the continual reuse and exchange or transfer of old equipment within and across beekeeping operations, which can lead to the spread of various pathogens and parasites (Cox-Foster et al., 2007; Fries and Camazine, 2001; Pettis et al., 2007; vanEngelsdorp et al., 2009a; vanEngelsdorp and Meixner, 2010). The fungal agent of the larval disease chalkbrood (CB; Ascosphaera apis) produces spores that can remain viable in wax comb and can be spread throughout a colony and among colonies when adult bees clean the comb and transfer spores to developing larvae (Aronstein and Murray, 2010; Flores et al., 2005). The same is true for spores of Nosema spp. (Fries, 1988; Higes et al., 2010) and AFB (Hansen and Brødsgaard, 1999; Haseman, 1961). Additionally, recent evidence suggests that at least some viruses can be found in wax comb ((Colwell

\footnotetext{
* Corresponding author at: USDA-ARS, 1157 Ben Hur Rd, Baton Rouge, LA 77820, USA.

E-mail address: michael.simonefinstrom@ars.usda.gov (M. Simone-Finstrom).
} 
et al., 2017); Simone-Finstrom, Rinkevich and de Guzman, preliminary data), which could potentially serve as a point of infection. Investigations regarding treatments that better facilitate the use of older comb have been of significant interest, particularly with respect to AFB-infected comb as the current standard practice is to burn contaminated equipment (Hansen and Brødsgaard, 1999). Therefore, treatments that work against multiple pathogens and parasites, especially viruses, where there are no treatments available for honey bees, can have a significant positive impact on the health and productivity of honey bee colonies and thus, profitability for beekeeping operations.

One method that has been explored over the years is the use of gamma irradiation for sterilization of hive components (Hornitzky, 1994). Gamma irradiation is commonly used throughout the agricultural and human health industries to sterilize equipment and food products (ISO\#13409, 2002; Sommers, 2012). Much of the previous work on sterilization of bee equipment has focused on its effectiveness against AFB-contaminated comb. Several studies have shown that a dose of $10 \mathrm{kGy}$ is an effective treatment to inactivate AFB spores for the reuse of equipment (Baggio et al., 2005; De Guzman et al., 2011; Gochnauer and Hamilton, 1970; Gosselin and Charbonneau, 1990). More recent work has provided some evidence that gamma irradiation may prevent colony losses when bees are hived on old comb that has been treated (Cox-Foster et al., 2007; Pettis et al., 2007). Other research has focused on the use of gamma irradiation to sterilize bee-collected pollen before feeding it to commercially reared bumblebees to limit the spread of pathogens. These studies have shown that gamma irradiation can inactivate viruses (Meeus et al., 2014) and reduce the frequency of detecting various pathogen and parasite DNA/RNA in pollen (including DWV, BQCV, and Nosema; Graystock et al., 2016). However, gamma irradiation does not eliminate or completely reduce infectivity of all pathogens, including $N$. ceranae and the parasitic protozoan Apicystis bombi, in particular (Graystock et al., 2016). Incomplete inactivation has also been noted for the bacterial agent that causes the larval disease European foulbrood (Pankiw et al., 1970). Conditions of irradiation, including sample preparation, can also impact the ability of gamma irradiation to inactivate certain types of viruses (Hume et al., 2016; Thomas et al., 1981). With this in mind, assays that examine infectivity post-irradiation are of critical importance to understand the relevance of such a treatment.

The aim of the current study was to investigate the potential of gamma irradiation to inactivate multiple honey bee pathogens that can be found in hive products. Since much of the previous work regarding honey bees have focused on bacterial pathogens, here we examined the infectivity of CB (a fungal pathogen), $N$. ceranae (a microsporidian gut parasite), the two most prevalent bee viruses-Deformed wing virus (DWV) and Black queen cell virus (BQCV) (Chen and Siede, 2007; Traynor et al., 2016), and a potential emerging viral threat-Chronic bee paralysis virus (CBPV) (Ribière et al., 2010; Traynor et al., 2016). These pathogens impact different honey bee life stages and represent a larger swath of the potential infections that honey bees face. Understanding how gamma irradiation may reduce the infectivity of this suite of pathogens provides supporting evidence for the use of gamma irradiation to sterilize bee equipment.

\section{Materials and methods}

Three batches of each of the following pathogen/parasite solutions were prepared for the following treatments: (1) untreated stock solution, not transported nor irradiated but stored at $4{ }^{\circ} \mathrm{C}$ until use (stock); (2) stock solution transported to the irradiation facility without being irradiated (transported); and (3) stock solution transported to the irradiation facility for irradiation (irradiated). The transportation and process of irradiation were completed over 5 days in Spring 2016 and over 3 days in Summer 2017.

The irradiation treatment was conducted at an USDA/APHIS certified phytosanitary treatment facility (Gateway America, Gulfport, MS).
Stock solutions were contained in $1.5 \mathrm{~mL}$ microcentrifuge tubes in cardboard boxes (transported) or in ziploc bags stapled to the inside wall of a commercial, wooden Langstroth hive box (irradiated). The transported stock solutions remained in the same warehouse where the irradiated solutions were kept and treated and were maintained at $28^{\circ} \mathrm{C}$. Thereafter, the transported solutions were brought to the laboratory at the same time as the irradiated group. The irradiated stock solutions were exposed to $25 \mathrm{kGy}$ of gamma irradiation delivered over $9 \mathrm{~h} 45 \mathrm{~min}$, which is a standard dose used for sanitization purposes (ISO\#13409, 2002).

\subsection{Chalkbrood (CB)}

Chalkbrood (Ascosphaera apis) spores were collected following wellestablished methods (Aronstein et al., 2015; Aronstein and Murray, 2010). Briefly, an A. apis strain (BBR) isolated from previous work (Aronstein and Murray, 2010) was grown on YGPSA (1\% yeast extract, $1 \%$ glucose, $0.1 \mathrm{M} \mathrm{KH}_{2} \mathrm{PO}_{4}, 1 \%$ soluble starch, and $2 \%$ agar) solid culture medium with $100 \mu \mathrm{g} / \mathrm{mL}$ ampicillin sodium salt and $6 \mu \mathrm{g} / \mathrm{mL}$ streptomycin sulfate. Plates were incubated at $33^{\circ} \mathrm{C}$ for 7 days and then at room temperature for an additional 3 days. Ascospores, the sexual stage of ascomycetes fungi, were harvested from culture plates and stored at $4^{\circ} \mathrm{C}$.

\subsubsection{Growth assessment}

After the vials containing $\mathrm{CB}$ returned from the irradiation facility, spores were tested for viability by plating $\sim 10^{4}$ spores following the same protocol used to culture the spores. Three plates were prepared for each of the three treatments (stock, transported, and irradiated) and monitored for growth and sporulation for 2 weeks at $33^{\circ} \mathrm{C}$.

\subsubsection{Infectivity of $C B$ spores in in vitro-reared larvae}

To examine infectivity, individual larvae were inoculated in vitro with CB spores. In vitro rearing of larvae followed modifications of standard protocols (Aupinel et al., 2005; Crailsheim et al., 2013). First instar larvae were grafted to plastic queen cell cups and mass provisioned with $190 \mathrm{mg}$ of larval rearing diet (50\% royal jelly, $6 \%$ glucose, $6 \%$ fructose, $1 \%$ yeast extract). Preliminary work has found $190 \mathrm{mg}$ to be the optimum amount of diet needed by a first instar larva to complete its development through eclosion to an adult worker bee (SimoneFinstrom, unpublished data). Larvae were treated topically near the mouthparts with $10^{4} \mathrm{CB}$ spores in $5 \mu \mathrm{L}$ water just after grafting. Control larvae were treated with water only. There were a total of four treatments: control $(n=24)$, stock $(n=16)$, transported $(n=16)$, and irradiated $\left(\mathrm{n}=32\right.$ ). Larvae were maintained at $34^{\circ} \mathrm{C}$ and $85 \%$ relative humidity and monitored daily for survival and development of symptoms until pupation.

Differences in survival were compared between the 4 treatment groups using the Kaplan-Meier survival analysis (JMP Pro 12), followed by post hoc pair-wise analysis when there was a significant effect from treatment.

\subsection{Black queen cell virus (BQCV)}

Ten symptomatic queen larvae collected in early Spring 2016 and stored at $-80^{\circ} \mathrm{C}$ were homogenized in $10 \mathrm{~mL}$ sterilized phosphate buffered saline (PBS). The viral solution was semi-purified (de Miranda et al., 2013) by centrifugation in a $15 \mathrm{~mL}$ tube at $4700 \mathrm{~g}$ for $20 \mathrm{~min}$ at $4^{\circ} \mathrm{C}$. The supernatant was filtered with $0.22 \mu \mathrm{m}$ syringe filter, and divided into thirds and stored at $4{ }^{\circ} \mathrm{C}$ until use.

Identification and quantification of virus in the solution was confirmed by qPCR following standard methods (Boncristiani et al., 2013; de Miranda et al., 2013). The region encoding a capsid protein of BQCV was amplified using Forward-TTT AGA GCG AAT TCG GAA ACA and Reverse-GGC GTA CCG ATA AAG ATG GA primers [(vanEngelsdorp et al., 2009b); (HQ655494.1)]. 


\subsubsection{Infectivity of $B Q C V$ in in vitro-reared larvae}

Infectivity of BQCV was first examined in larvae reared in vitro, which is the main stage of development affected by this virus. Larvae were reared as described above (Section 2.1.2), with one exception. In this case, larvae were mass provisioned with $235 \mathrm{mg}$ of larval diet, an amount previously found to produce bees that are queen-like under in vitro conditions (Simone-Finstrom, unpublished data). The viral solutions (stock, transported and irradiated) were diluted 1:125 in sterile PBS, which corresponded to $10^{10}$ viral copies, and $5 \mu \mathrm{L}$ was topically applied near the mouthparts of each larva. Control larvae were treated with sterile PBS. Twenty larvae per treatment (control, stock, transported, and irradiated) were monitored daily for mortality and presentation of symptoms for 12 days. Survival data were analyzed as above (Section 2.1.2).

\subsubsection{Virus injection assay}

To examine infectivity and the ability of BQCV to replicate, whiteeyed worker pupae from a single source colony were injected with the viral solutions from the different treatment groups. Pupae were injected with $3 \mu \mathrm{L}$ of $10^{10} \mathrm{BQCV}$ copies ( $\mathrm{n}=35$ per treatment) or $10^{8} \mathrm{BQCV}$ copies ( $\mathrm{n}=15$ per treatment) for each of the three treatment solutions (stock, transported, or irradiated) using a Hamilton syringe fitted with a $30 \mathrm{G}$ needle at an infusion rate of $1 \mu \mathrm{L} / \mathrm{s}$ using a Micro4 ${ }^{\mathrm{TM}}$ Microsyringe Pump Controller adapted from standard methods (Boncristiani et al., 2013; de Miranda et al., 2013). PBS injections (control) were completed on another 35 pupae. Pupae were maintained on filter paper in petri dishes at $34^{\circ} \mathrm{C}$ and $80 \%$ relative humidity. Mortality was assessed daily for 3 days, after which all pupae were frozen at $-80^{\circ} \mathrm{C}$ for analysis of viral replication by $q$ PCR.

Eight pupae per treatment (control, stock, transported, and irradiated) were assessed for viral loads 3-days post-injection in 2016. RNA extractions were completed using the Maxwell ${ }^{\circledR} 16$ LEV simplyRNA system (Promega) and cDNA template was generated from $2 \mu \mathrm{g}$ of total RNA using the QuantiTect Reverse Transcription Kit (Qiagen) following the manufacturer's instructions. qPCR was performed in triplicate with a QuantStudio ${ }^{\mathrm{TM}} 6$ Flex System (Applied Biosystems) using $2 \mu \mathrm{L}$ of cDNA template per $20 \mu \mathrm{L}$ reaction containing $1 \mathrm{X}$ PowerUP ${ }^{\mathrm{TM}}$ SYBER $^{\circledast}$ Green (ThermoFisher Scientific). The thermal profile was as follows: $2 \mathrm{~min}$ at $50{ }^{\circ} \mathrm{C}$ then $2 \mathrm{~min}$ at $95^{\circ} \mathrm{C}$, followed by 45 cycles of $95^{\circ} \mathrm{C}$ for $15 \mathrm{sec}$, $53.5^{\circ} \mathrm{C}$ for $20 \mathrm{sec}$, and $72{ }^{\circ} \mathrm{C}$ for $30 \mathrm{~s}$. A melt-curve dissociation analysis completed each run.

Black queen cell virus titers were determined using standard curves generated from plasmid standards containing the sequence listed above (generated by GeneArt, Invitrogen). Linearized plasmid standards containing $10^{5}$ to $10^{12}$ copies per reaction were used as templates to assess primer efficiency and quantify the amount of virus following standard practices (Cavigli et al., 2016; Hou et al., 2010). Linear standard equations were generated using the $\log _{10}$ of the initial plasmid copy number. Differences in copy number across treatments were then expressed as the ratio of BQCV in virus-injected samples to the average level of BQCV in PBS controls, log-transformed and analyzed via oneway ANOVA (JMP Pro 12).

A second trial in 2017 was conducted to confirm mortality results. As described above, pupae from two unrelated colonies were injected with $10^{10} \mathrm{BQCV}$ copies and monitored for 7 days after injection.

\subsection{Deformed wing virus (DWV)}

Deformed wing virus was obtained using a similar protocol that was used to isolate BQCV. Twenty bees symptomatic for DWV were homogenized in $20 \mathrm{~mL}$ sterile PBS. Deformed wing virus was semipurified as in Section 2.2 and the identity of the virus was confirmed via qPCR and maintained at $4{ }^{\circ} \mathrm{C}$ until use.

In 2016, DWV infectivity and replication was examined using methods and analysis as described above (Section 2.2.2). The region of DWV amplified was based on the following primers: Forward-GAG
ATT GAA GCG CAT GAA CA; Reverse-TGA ATT CAG TGT CGC CCA TA [(vanEngelsdorp et al., 2009b); (AY292384.1)]. Briefly, pupae were injected with $10^{9}\left(\mathrm{n}=35\right.$ per treatment) or $10^{7}$ viral copies $(\mathrm{n}=15$ per treatment) of viral solution or sterile PBS only $(n=35)$. Differences in copy number across treatments were expressed as the ratio of DWV in virus-injected samples to the average of DWV in PBS-injected controls, $\log$ transformed and analyzed by Welch's ANOVA due to unequal variances across treatment groups.

Mortality results were confirmed in 2017 by injecting pupae from two unrelated colonies with $10^{10}$ DWV copies or PBS alone, and monitored for 7 days post-injection for presentation of symptoms at emergence.

\subsection{Chronic bee paralysis virus (CBPV)}

Chronic bee paralysis virus was also obtained as previously described (Section 2.2). In 2017, 20 bees symptomatic for CBPV were homogenized in $20 \mathrm{~mL}$ sterile PBS. Chronic bee paralysis virus was semi-purified and the identity of the virus was confirmed via qPCR and maintained at $4{ }^{\circ} \mathrm{C}$ until use. A region of the CBPV genome was amplified using the following primers: Forward-CGC AAG TAC GCC TTG ATA AAG AAC; Reverse-ACT ACT AGA AAC TCG TCG CTT CG [(Blanchard et al., 2007); (EU122229.1)]. To examine infectivity and replication, 30 pupae per treatment (stock, transported, and irradiated) were injected with a solution containing $10^{7} \mathrm{CBPV}$ copies. Test pupae were obtained from two colonies. All but 4 of the $180 \mathrm{CBPV}$-injected pupae were necrotic $24 \mathrm{~h}$ post-injection. Pupae were frozen at $-80^{\circ} \mathrm{C}$ for analysis of viral replication. Fifteen pupae from each of two colonies per treatment were analyzed for viral load. Differences in copy number across treatments were expressed as the ratio of CBPV in the virus-injected samples to the average level of CBPV in PBS-injected controls, log-transformed, and analyzed via one-way ANOVA with colony source included as a random effect.

\subsection{Nosema ceranae}

Midguts from 40 foragers were collected from a local colony with a high level of $N$. ceranae infection. Midguts were macerated in $5 \mathrm{~mL}$ sterile water producing a solution that contained $\sim 2.9 \times 10^{4}$ spores/ $\mu \mathrm{L}$. The spore solution was maintained at $4{ }^{\circ} \mathrm{C}$. The identity of $N$. ceranae spores was confirmed by PCR following standard methods (Fries et al., 2013).

\subsubsection{Infectivity of Nosema ceranae in caged bees}

To examine the infectivity of $N$. ceranae spores, an analysis of spore reproduction in newly emerged bees was conducted. Each of the spore solutions was diluted 1:1 in 50\% sucrose solution. Concentrations of spore solutions were reconfirmed prior to inoculation and the following doses were given in $5 \mu \mathrm{L}$ to 30 newly emerged bees per treatmentstock: 42,800 spores; transported: 37,600 spores; irradiated: 38,200 spores; control (sugar syrup): 0 spores.

Bees were placed in cages and given sucrose syrup and water ad libitum. Another 20 untreated bees were paint-marked on the thorax and added to each cage to increase the population in the cages to a sustainable level. Bees were maintained at $30^{\circ} \mathrm{C}$ with $\sim 65 \%$ relative humidity in a controlled incubator (Huang et al., 2014). After 7 days, the experiment was terminated to assess Nosema infectivity and reproduction. Bees were stored at $-20^{\circ} \mathrm{C}$ until spore loads were determined using standard methods (Fries et al., 2013). Those performing the spore counts were blind to the treatment designations. Analysis of Nosema infection was performed by calculating the log ratio of the 7day spore load to the original spore dose to account for the slight difference in the initial doses. The difference in the change in spore load due to treatment was analyzed by Welch ANOVA due to unequal variances across treatment groups (JMP Pro 12). 


\subsubsection{Germination assay}

Solutions containing $N$. ceranae spores were shipped to the University of Minnesota, Twin Cities, to determine spore viability. Solutions were stored in the dark at room temperature for 6 weeks until the assay could be completed. To conduct the germination assay, the solutions were vortexed and $2 \mu \mathrm{L}$ of each was placed onto a glass slide. This was replicated 6 times per solution. The slides were allowed to airdry for $10 \mathrm{~min}$ at room temperature in a laminar flow hood. Then, $10 \mu \mathrm{L}$ of a $0.5 \mathrm{M} \mathrm{NaCl} / 0.5 \mathrm{NaHCO}_{3}$ (pH to 6.0 with phosphoric acid) germination solution was placed over the dried spot. The slides were coverslipped and incubated at $37{ }^{\circ} \mathrm{C}$ and $90 \%$ relative humidity for $30 \mathrm{~min}$. After $30 \mathrm{~min}$, the number of germinated spores was counted by evidence of an extruded polar filament at $400 \times$ with phase contrast microscopy. Ten different fields of view were chosen at random, and 10 spores within each field were counted along a transect. A total of 100 spores were counted per slide with a total of 600 spores being counted per treatment. Counts were conducted blindly with respect to treatment. Differences due to treatment in percent germination of spores within the 10 fields of view were analyzed by Welch ANOVA due to unequal variances across treatment groups (JMP Pro 12).

\section{Results}

\subsection{Chalkbrood}

Chalkbrood spore development and normal growth of cultures of $A$. apis were observed for spores that were maintained at $4{ }^{\circ} \mathrm{C}$ (stock) and those that were transported, but not the irradiated spores (Fig. 1A). Similarly, larvae that were inoculated with irradiated spores had higher survival and did not develop symptoms of CB infection, unlike those fed stock or transported spores (Fig. 1B). Significant differences in lifespan were detected among larvae inoculated with stock or transported $A$. apis spores versus larvae fed spores that were irradiated or no spores (control) $\left(\chi^{2}=67.68, \mathrm{df}=3, P<0.0001\right.$; Fig. 2).

\subsection{Black queen cell virus}

\subsubsection{Infectivity of $B Q C V$ in in vitro-reared larvae}

Larvae were inoculated with solutions containing stock, transported, and irradiated BQCV or a control solution without virus. Mortality and development of symptoms were assessed for 12 days. Most mortality was asymptomatic, though some treated larvae did exhibit typical BQCV symptoms (Simone-Finstrom, personal observations). Overall, control mortality was higher than was seen in the $\mathrm{CB}$ assays (Fig. 2), largely due to the increased amount of diet as has been

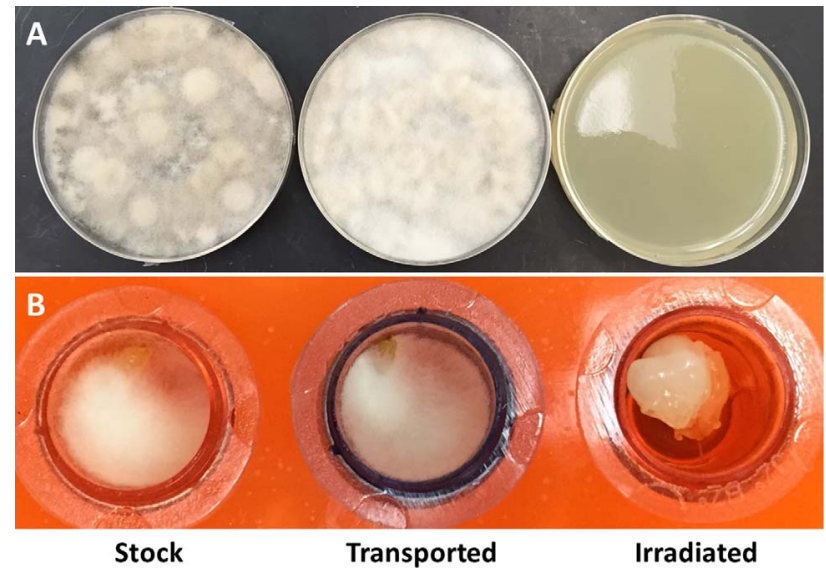

Fig. 1. Growth of Ascosphaera apis in cultures or in in vitro-reared larvae. (A) Growth of spores in cultures after $96 \mathrm{~h}$. (B) Development of chalkbrood symptoms in a larva treated with either stock or transported spores versus a larva inoculated with irradiated spores. Control (inoculated without spores) not pictured.

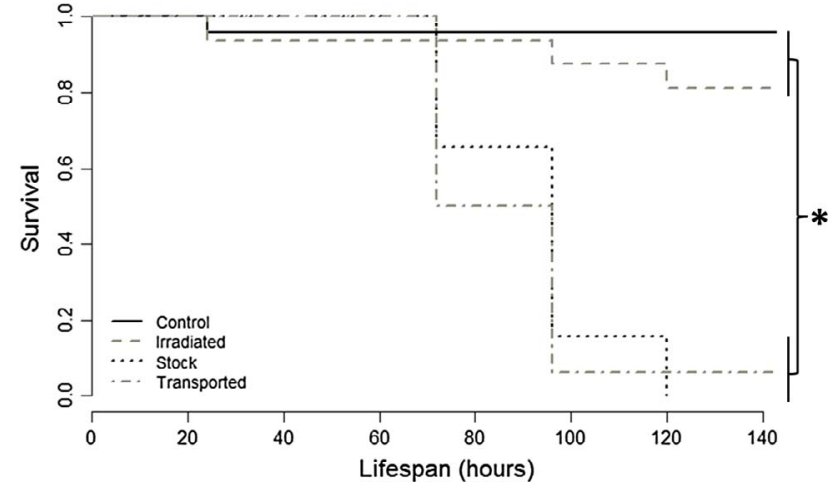

Fig. 2. Proportion of honey bee larvae surviving over time after inoculation with chalkbrood spores. Curves with an overlapping bar were not significantly different $(P>0.05)$ based on pairwise post hoc analysis.

noted in previous research (Linksvayer et al., 2011; Simone-Finstrom, unpublished data). Significant differences in lifespan were seen among larvae inoculated with stock or transported solutions containing BQCV versus larvae inoculated with irradiated or control solutions $\left(\chi^{2}=9.69, \mathrm{df}=3, P=0.021\right.$; Fig. 3). The mean time to death was $213.6 \pm 21.5 \mathrm{~h}$ for BQCV stock, $235.2 \pm 17.1 \mathrm{~h}$ for the transported solution, $276 \pm 6.0 \mathrm{~h}$ for the irradiated solution, and $274.8 \pm 5.6 \mathrm{~h}$ for the PBS control treated larvae.

\subsubsection{Virus injection assay with $B Q C V$}

In 2016, pupae injected with stock, transported, or irradiated solutions containing BQCV exhibited varying levels of survival $3 \mathrm{~d}$ postinjection and each solution caused arrested development and acute mortality in some individuals (see Table 1 and Fig. 4A). The proportion of surviving pupae injected with the irradiated solution, however, was higher than that for pupae injected with stock or transported solutions, though less than pupae injected with PBS alone $\left(\chi^{2}=78.18, \mathrm{df}=6\right.$, $P<0.0001)$. Post-hoc analysis indicated that this difference was only for the higher dose $\left(\chi^{2}=16.50, \mathrm{df}=2, P=0.0003\right)$, while at the lower dose all three BQCV solutions produced mortality in equivalent proportions $\left(\chi^{2}=1.25, \mathrm{df}=3, P<0.53\right.$ ). In 2017, all pupae injected with the stock, transported, and irradiated solutions of BQCV were dead or had arrested development 7 days post-injection (Table 2). Therefore it is possible that if the mortality was assessed at 7 days post-injection in 2016 those pupae that appeared to be progressing in normal development might have actually been in an arrested state and potentially would have died by 7 days.

There was a significant difference in viral replication across treatments. The amount of BQCV 3 days post-injection, as analyzed in the 2016 samples, was significantly less for the irradiated treatment as

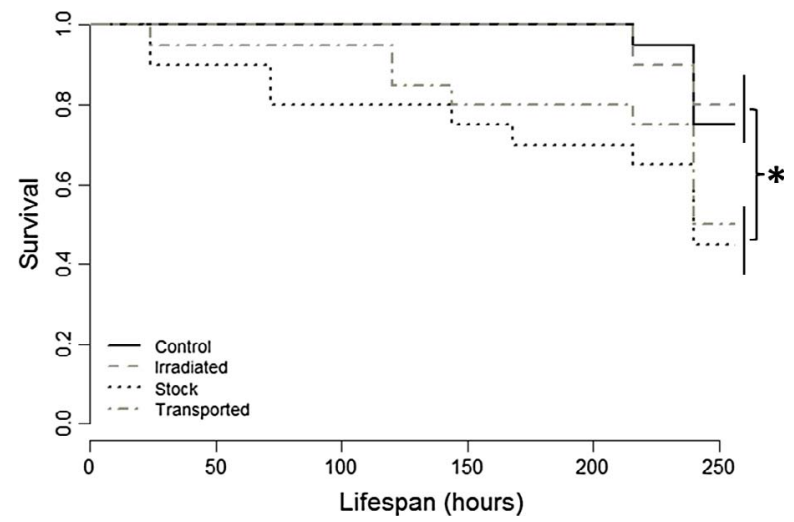

Fig. 3. Proportion of larvae surviving over time after challenge with BQCV. Curves with an overlapping bar were not significantly different $(P>0.05)$ based on pairwise post hoc analysis. 
Table 1

Pupal mortality 3 days post-injection for 2016 trials. Mortality includes pupae that were in a state of arrested development (based on lack of developmental progression or no increased eye pigmentation) or dead (development of necrotic tissue). Results for BQCV-, DWV-, and control-injected pupae are shown.

\begin{tabular}{lllll}
\hline Virus & Dose & Treatment & $\mathrm{N}$ & $\%$ Mortality \\
\hline None & PBS & Control & 35 & $0 \%$ \\
BQCV & $10^{10}$ copies & Stock & 35 & $80 \%$ \\
& $10^{8}$ copies & Stock & 15 & $46.7 \%$ \\
& $10^{10}$ copies & Transported & 35 & $80 \%$ \\
& $10^{8}$ copies & Transported & 15 & $60 \%$ \\
& $10^{10}$ copies & Irradiated & 35 & $40 \%$ \\
& $10^{8}$ copies & Irradiated & 15 & $40 \%$ \\
DWV & $10^{9}$ copies & Stock & 35 & $100 \%$ \\
& $10^{7}$ copies & Stock & 15 & $100 \%$ \\
& $10^{9}$ copies & Transported & 35 & $100 \%$ \\
& $10^{7}$ copies & Transported & 15 & $100 \%$ \\
& $10^{9}$ copies & Irradiated & 35 & $0 \%$ \\
& $10^{7}$ copies & Irradiated & 15 & $0 \%$ \\
\hline
\end{tabular}

A
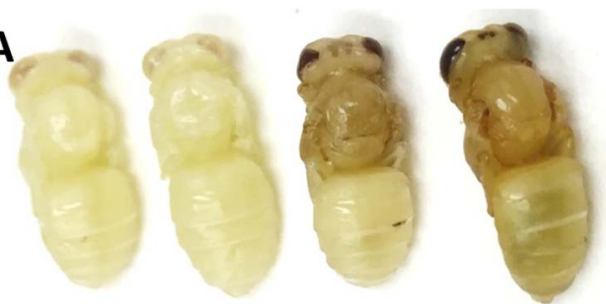

BQCV

B

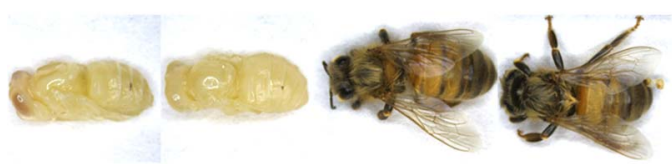

DWV

\section{Stock Transported Irradiated Control}

Fig. 4. Representative pupae injected with viral solutions. (A) Examples of the arrested development of pupae injected with stock and transported BQCV solutions 3 days postinjection versus typical development (e.g. darkening of eye pigmentation) seen in pupae injected with the irradiated and control solutions. (B) Injection of the DWV stock and transported solutions caused arrested development at 7 days post-injection, with little progression beyond the pink-eyed stage, while pupae injected with PBS control and irradiated DWV solutions exhibited normal development and emerged without overt expression of DWV symptoms.

Table 2

Pupal mortality 7 days post-injection for 2017 trials. Mortality includes pupae that were in a state of arrested development (based on lack of developmental progression or no increased eye pigmentation) or dead (development of necrotic tissue). Results for BQCV-, CBPV-, DWV- and control-injected pupae are shown combining pupae from both colonies tested as there were no differences seen across colonies. "CBPV mortality was recorded $24 \mathrm{~h}$ post-injection.

\begin{tabular}{lllll}
\hline Virus & Dose & Treatment & $\mathrm{N}$ & $\%$ Mortality \\
\hline None & PBS & Control & 27 & $11.1 \%$ \\
BQCV & $10^{10}$ copies & Stock & 27 & $100 \%$ \\
& $10^{10}$ copies & Transported & 28 & $100 \%$ \\
& $10^{10}$ copies & Irradiated & 27 & $100 \%$ \\
DWV & $10^{10}$ copies & Stock & 28 & $100 \%$ \\
& $10^{10}$ copies & Transported & 28 & $100 \%$ \\
& $10^{10}$ copies & Irradiated & 28 & $3.6 \%$ \\
CBPV $^{*}$ & $10^{7}$ copies & Stock & 60 & $96.7 \%$ \\
& $10^{7}$ copies & Transported & 60 & $98.3 \%$ \\
& $10^{7}$ copies & Irradiated & 60 & $98.3 \%$ \\
\hline
\end{tabular}
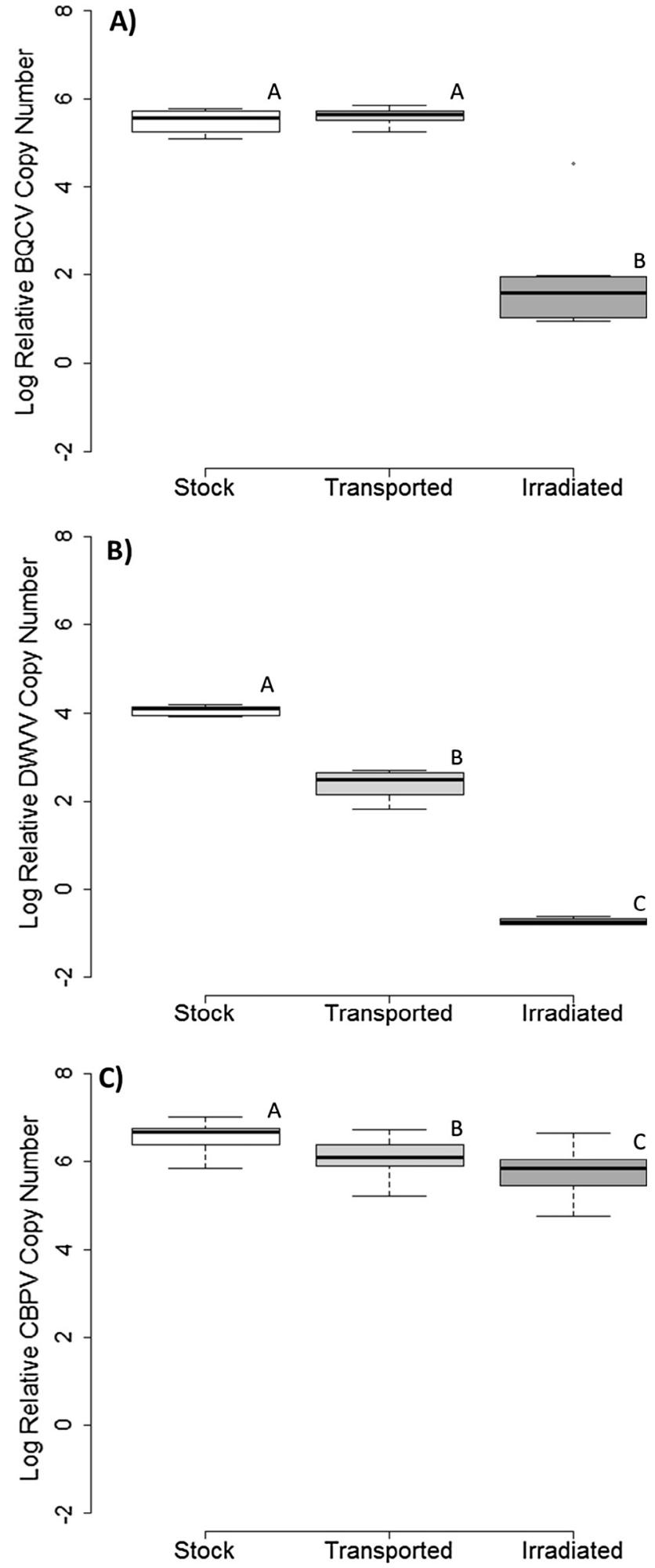

Fig. 5. Viral loads of bees 3 days post-injection with (A) BQCV or (B) DWV or (C) $24 \mathrm{~h}$ after injection with CBPV. Viral copy number is expressed as the log of the ratio to the average of the PBS-injected bees. Different letters indicate significant differences across treatment groups. 
compared to the stock or transported treatments $\left(F_{2,20}=65.63\right.$, $P<0.0001$; Fig. 5A). The mean copy number for each treatment was as follows: stock-1.1 $\times 10^{10} \quad(\mathrm{n}=8)$, transported-1.3 $\times 10^{10}$ $(\mathrm{n}=8)$, irradiated-1.3 $\times 10^{8}(\mathrm{n}=7)$, and PBS-2.9 $\times 10^{4}(\mathrm{n}=8)$.

\subsection{Deformed wing virus}

Pupae injected with the different DWV solutions exhibited clear differences with respect to mortality 3 days post-injection in 2016 (see Table 1; Fig. 4B) and at 7 days post-injection in 2017 (Table 2). All of the pupae injected with the stock and transported DWV solutions either experienced arrested development or acute mortality at both higher and lower concentrations. However, all of the pupae injected with the irradiated DWV solutions or the PBS control solution were alive and displayed the normal course of development after 3 days in 2016 and after 7 days in 2017. All of the adult bees injected with PBS and the irradiated DWV solution were asymptomatic.

In terms of viral replication, there were differences across treatments. The amount of DWV 3 days post-injection was the lowest for irradiated treatment, followed by the transported treatment and highest in the stock $\left(\mathrm{F}_{2,19}=916.83, P<0.0001\right.$; Fig. $\left.5 \mathrm{~B}\right)$. The mean copy number for each treatment group was as follows: Stock-5.3 $\times 10^{9}$ $(\mathrm{n}=8), \quad$ Transported-1.3 $\times 10^{8} \quad(\mathrm{n}=8), \quad$ Irradiated-8.5 $\times 10^{4}$ $(\mathrm{n}=6)$, and PBS-4.5 $\times 10^{5}(\mathrm{n}=8)$.

\subsection{Chronic bee paralysis virus}

All but four pupae injected with the various CBPV solutions developed necrotic tissue within $24 \mathrm{~h}$ post-injection (Table 2). The amount of CBPV in injected pupae collected 7-days post-injection was lowest in the irradiation treatment, moderate in the transported treatment and highest in the stock $\left(\mathrm{F}_{2,70}=22.86, P<0.0001\right.$; see Fig. $\left.5 \mathrm{C}\right)$. The mean copy number for each treatment group was as follows: Stock-1.9 $\times 10^{10}(\mathrm{n}=23)$, Transported-6.9 $\times 10^{9} \quad(\mathrm{n}=24)$, Irradiated-3.9 $\times 10^{9}(\mathrm{n}=24)$, and PBS-5.5 $\times 10^{3}(\mathrm{n}=16)$.

\subsection{Nosema ceranae}

$N$. ceranae spore loads were assessed 7 days post-inoculation. The change in number of $N$. ceranae spores (ratio of spores at 7 days to inoculation dose) was significantly different due to treatment $\left(\mathrm{F}_{2,87}=36.67, P<0.0001\right.$; Fig. 6). Worker bees fed transported spores exhibited the highest increase in spore load (mean ratio \pm standard deviation: $63.21 \pm 91.25$ ), followed by bees fed the stock solution (18.16 \pm 23.40$)$, with the lowest change in Nosema levels in the irradiated group $(0.99 \pm 0.82)$. Twenty un-inoculated bees were

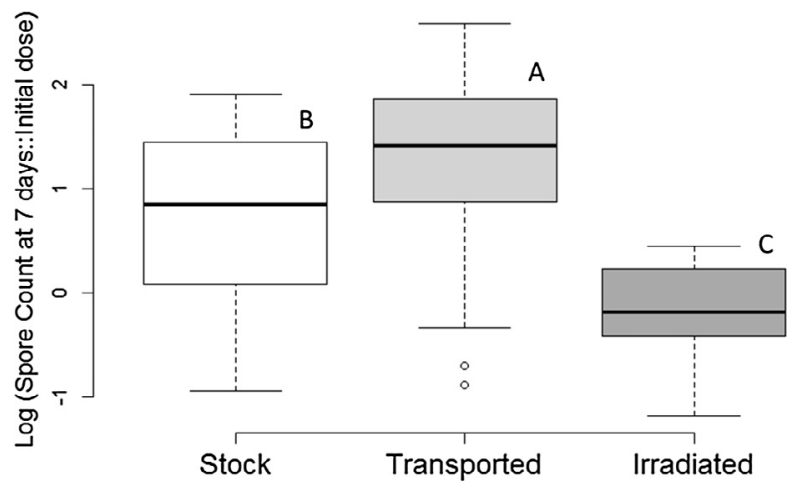

Fig. 6. Spore loads in Nosema-infected bees 7 days post-inoculation. Spore counts are presented as the log ratio of Nosema spores after 7 days compared to the original dose. A value above 0 indicates that Nosema increased in spore number in the honey bee gut, while a value of 0 indicates no change in spore number from the original inoculum. Different letters above each box plot indicate significant differences.

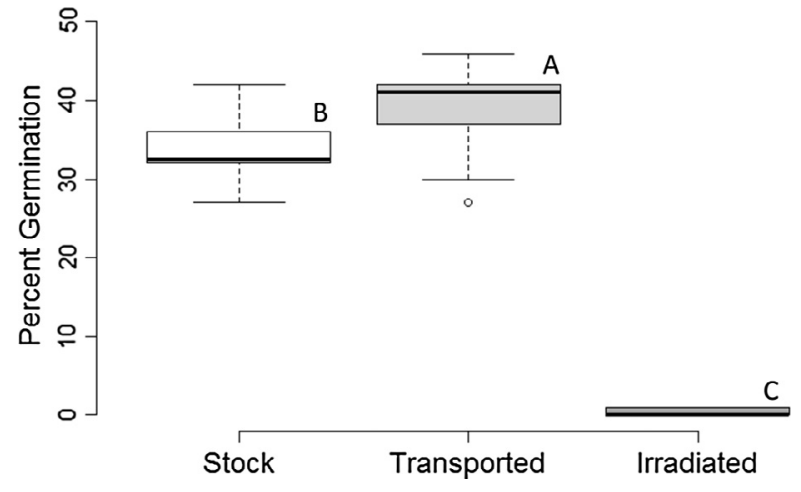

Fig. 7. Percent germination of Nosema ceranae spores that were irradiated, transported, or remained at $4^{\circ} \mathrm{C}$ (stock). Different letters above each bar indicate significant differences.

also sampled from cages containing inoculated bees and were found to be free of Nosema infection (data not shown). Variation across individuals within treatments was likely, at least in part, due to inaccuracy during the inoculation procedure, though bees given stock and transported solutions containing Nosema largely saw increases with respect to spore levels, while those fed the irradiated solution saw little change in spore counts.

This finding was corroborated by the germination assay. Showing the same pattern as the inoculation assay, the percent germination was highest for the transported spores $(39.1 \pm 6.2 \%)$, followed by the stock spores $(33.8 \pm 4.3 \%)$, with the irradiated spores having the lowest $(0.48 \pm 0.42 \%)\left(\mathrm{F}_{2,27}=464.6, P<0.0001\right.$; Fig. 7).

\section{Discussion}

Previous work on the effectiveness of gamma irradiation against honey bee pathogens has focused mainly on the bacterial brood pathogen American foulbrood (Baggio et al., 2005; De Guzman et al., 2011; Gosselin and Charbonneau, 1990). Our results also showed that gamma irradiation effectively rendered the fungus Ascosphaera apis (CB), the microsporidian gut parasite Nosema ceranae, and Deformed wing virus (DWV) inactive and reduced infectivity of Black queen cell virus (BQCV). We found less of an effect of irradiation on Chronic bee paralysis virus (CBPV). These results suggest that gamma irradiation has a relatively broad effect against a suite of honey bee pathogens and highlights its potential as a treatment to reduce the impacts of pathogens harbored in older wax combs that are often exchanged among colonies and even beekeeping operations.

DWV showed a high level of inactivity in response to gamma irradiation. All pupae injected with the irradiated viral solution survived while none of the pupae injected with the stock or transported viral solutions survived at either a high or low dose. It is interesting to note that the same level of inactivation was not seen for BQCV. Despite the effect of slightly reducing viral replication, irradiation of the BQCV solution did not completely eliminate negative effects as some pupae died or experienced arrested development at 3 days post-injection in 2016 and all pupae injected with irradiated BQCV were dead or had arrested development at 7 days post-injection in the 2017 trials. Although there were clear effects for BQCV in vitro reared larvae, its effectiveness was not quite as strong as compared to DWV, CB or $N$. ceranae. Alternatively, irradiation had little to no effect against CPBV at the dose tested since nearly all of the injected pupae developed necrotic tissue within $24 \mathrm{~h}$. While DWV and BQCV are both positive-sense singlestranded RNA viruses with icosahedral shape and similar size (de Miranda et al., 2013), they do have two different forms of genomic organization and are assigned to the genera Ilfavirus and Cripavirus, respectively. DWV has a single, large open reading frame, which could possibly make it more sensitive to irradiation, versus the fact that BQCV has two non-overlapping open reading frames. In addition, the genome 
of DWV is monopartite monocistronic, while BQCV is monopartite bicistronic and this structural difference could result in BQCV being able to more efficiently translate proteins during cellular invasion and thus, infection (Chen and Siede, 2007), and therefore it may be more resilient against damage from irradiation. Chronic bee paralysis virus is unlike the other RNA honey bee viruses in that it is not isometric, has an unusual viral capsid, and has a unique genomic structure comprised of two major RNAs and seven putative open reading frames (Ribière et al., 2010). These factors could play a role in the limited effectiveness of gamma irradiation against this virus at the relatively high dose tested. If anything, it raises interesting questions and makes the clear point that examining infectivity post-irradiation is key to understanding the usefulness of treatments like gamma irradiation for pathogen control. It is possible that the low intensity and amount of radiation $(25 \mathrm{kGy}$ delivered over $9 \mathrm{~h} 45 \mathrm{~m}$ ) was not adequate to inactivate these viruses. Future experiments to assess the effects of irradiation parameters will yield more insight into effective methods of virus inactivation.

Similarly, the gamma irradiation treatment did not completely inhibit Nosema germination as 3 out of the 600 counted spores had an extruded polar filament indicating that some irradiated spores may remain infectious after treatment. Nevertheless, this low level of germination did not translate into an increase in spores in inoculated bees, unlike what may be suggested by work with bumblebees fed irradiated or non-irradiated pollen (Graystock et al., 2016). Perhaps the biological relevance of inhibited infectivity of treated Nosema spores carries more significance than germination rate. Similar findings have been shown for effects of gamma irradiation on $N$. apis (Liu et al., 1990), which has largely been replaced by $N$. ceranae in most of the US in recent years (Chen et al., 2008; Klee et al., 2007). Regardless, the conditions of irradiation (e.g. sample preparation, length of treatment) and the structure of the microorganism are factors to consider in how effective gamma irradiation may be for sterilization, particularly in the case of viruses (Sullivan et al., 1971). Further studies are needed to test infectivity and perhaps even dose response curves to determine the optimum dose of irradiation.

Lack of available therapeutics against viruses, in particular, provides a strong impetus for the investigation of high dose gamma irradiation as treatment of honey bee equipment. This is especially true as viral infections are major drivers of colony loss (Amiri et al., 2015; Cornman et al., 2012; Cox-Foster et al., 2007) and wax comb can harbor viruses ((Colwell et al., 2017); Simone-Finstrom, Rinkevich and de Guzman, unpublished data). Although RNAi feed treatment has been tested against Israeli acute bee paralysis virus (Hunter et al., 2010; Maori et al., 2009), it has not developed into a product accessible to the apicultural community. The only current "treatment" per se for various hive-borne diseases is to rotate old comb out of operations (Berry and Delaplane, 2001; Fries, 1988); however this might not be economically feasible in some operations. Given this, there has been much interest in treatments that sterilize comb, in addition to gamma irradiation. Fumigation with ethylene oxide was a popular option in the 1970s and 1980s, as it was effective against CB (Gochnauer and Margetts, 1980) but had variable success against AFB (Gochnauer et al., 1979). Ozone has also shown to be effective against $\mathrm{CB}$ and AFB, but only when combined with high temperature exposure, which may limit its usefulness for wax comb (James, 2011). More recent work has investigated the possibility of using double inductively coupled low pressure plasma (DICLPP) as a veterinary approved method of honey bee comb sterilization (Priehn et al., 2016); however, this method of treatment is not $100 \%$ effective against bacterial spores and requires operators to use lower than optimal temperatures during the treatment process. Based on previous studies indicating broad effects of gamma irradiation against AFB (Hornitzky, 1994), pollen sterilization (Graystock et al., 2016; Meeus et al., 2014), and this study, the utility of gamma irradiation in beekeeping operations warrants further investigation. It is key to consider infectivity of post-irradiated materials, however, in all future studies. Reductions in detection can be noted post-irradiation, but ultimately the functional infection rate and symptom development is still the most important factor for positive or negative effects regarding treatment, as seen with Nosema (small level of germination resulted in no infection) and the viruses CBPV and BQCV (reduced detection but still caused high mortality).

Subsequent studies aim to determine the potential long-term benefits that using gamma-irradiated comb in standard beekeeping practices can have on colony health and productivity. Since it has been suggested that placing colonies on irradiated comb may be beneficial (Cox-Foster et al., 2007; Pettis et al., 2007) and the work here has demonstrated clear, immediate effects against a suite of honey bee pathogens, the logical next step is to fully test the effects on actual honey bee colonies. Experiments are, in fact, underway to address this question.

\section{Acknowledgements}

We would like to acknowledge Bob Cox, Mandy Frake, Phil Tokarz, and Mia Sanchas for their assistance in conducting the various laboratory assays.

Mention of trade names or commercial products in this publication is solely for the purpose of providing specific information and does not imply recommendation or endorsement by the U.S. Department of Agriculture.

\section{Appendix A. Supplementary material}

Supplementary data associated with this article can be found, in the online version, at http://dx.doi.org/10.1016/j.jip.2018.02.011.

\section{References}

Amiri, E., et al., 2015. Four categories of viral infection describe the health status of honey bee colonies. PLoS ONE 10, e0140272.

Aronstein, K., et al., 2015. Validation of genetic markers associated with chalkbrood resistance. Trends Entomol. 11, 47-53.

Aronstein, K.A., Murray, K.D., 2010. Chalkbrood disease in honey bees. J. Invertebr. Pathol. 103 (Suppl.), S20-S29.

Aupinel, P., et al., 2005. Improvement of artificial feeding in a standard in vitro method for rearing Apis mellifera larvae. Bull. Insectol. 58, 107.

Baggio, A., et al., 2005. Gamma Radiation: a sanitating treatment of AFB-contaminated beekeeping eqiupment. Apiacta 40, 22-27.

Berry, J.A., Delaplane, K.S., 2001. Effects of comb age on honey bee colony growth and brood survivorship. J. Apic. Res. 40, 3-8.

Blanchard, P., et al., 2007. Evaluation of a real-time two-step RT-PCR assay for quantitation of Chronic bee paralysis virus (CBPV) genome in experimentally-infected bee tissues and in life stages of a symptomatic colony. J. Virol. Methods 141, 7-13.

Boncristiani, H.F., et al., 2013. In vitro infection of pupae with Israeli acute paralysis virus suggests disturbance of transcriptional homeostasis in honey bees (Apis mellifera). PLOS ONE 8, 11.

Cavigli, I., et al., 2016. Pathogen prevalence and abundance in honey bee colonies involved in almond pollination. Apidologie 47, 251-266.

Chen, Y., et al., 2008. Nosema ceranae is a long-present and wide-spread microsporidian infection of the European honey bee (Apis mellifera) in the United States. J. Invertebr. Pathol. 97, 186-188.

Chen, Y.P., Siede, R., 2007. Honey bee viruses. Adv. Virus Res. 70, 33-80.

Colwell, M.J., et al., 2017. Viruses in unexpected places: new transmission routes of European honey bee (Apis mellifera) viruses. In: In: Simone-Finstrom, M. (Ed.), American Bee Research Conference, vol. 93 Bee World, Galveston, TX.

Cornman, R.S., et al., 2012. Pathogen webs in collapsing honey bee colonies. PLoS ONE 7, 15 .

Cox-Foster, D.L., et al., 2007. A metagenomic survey of microbes in honey bee colony collapse disorder. Science 318, 283-287.

Crailsheim, K., et al., 2013. Standard methods for artificial rearing of Apis mellifera larvae. J. Apic. Res. 52, 15.

De Guzman, Z.M., et al., 2011. Radiation inactivation of Paenibacillus larvae and sterilization of American Foul Brood (AFB) infected hives using Co-60 gamma rays. Appl. Radiat. Isot. 69, 1374-1379.

de Miranda, J.R., et al., 2013. Standard methods for virus research in Apis mellifera. J. Apic. Res. 52, 1-56.

Evans, J.D., 2003. Diverse origins of tetracycline resistance in the honey bee bacterial pathogen Paenibacillus larvae. J. Invertebr. Pathol. 83, 46-50.

Flores, J., et al., 2005. Spores of Ascosphaera apis contained in wax foundation can infect honeybee brood. Vet. Microbiol. 108, 141-144.

Fries, I., 1988. Comb replacement and Nosema disease (Nosema apis Z.) in honey bee colonies. Apidologie 19, 343-354.

Fries, I., Camazine, S., 2001. Implications of horizontal and vertical pathogen 
transmission for honey bee epidemiology. Apidologie 32, 199-214.

Fries, I., et al., 2013. Standard methods for Nosema research. J. Apic. Res. 52, 1-28. Genersch, E., 2010. American Foulbrood in honeybees and its causative agent, Paenibacillus larvae. J. Invertebr. Pathol. 103 (Suppl.), S10-S19.

Gochnauer, T.A., et al., 1979. Large-scale fumigation with ethylene oxide of honeybee combs contaminated with Bacillus larvae. J. Apic. Res. 18, 302-308.

Gochnauer, T.A., Hamilton, H.A., 1970. Disinfection of honeybee combs by gamma irradiation I. American foul brood disease. J. Apic. Res. 9, 87-94.

Gochnauer, T.A., Margetts, V.J., 1980. Decontaminating effect of ethylene oxide on honeybee larvae previously killed by chalk-brood disease. J. Apic. Res. 19, 261-264.

Gosselin, P., Charbonneau, R., 1990. Disinfection of the bee hive's American foulbrood by gamma radiation from Cobalt-60. Int. J. Radiation Appl. Instrum.. Part C. Radiation Phys. Chem. 35, 292-295.

Graystock, P., et al., 2016. Hygienic food to reduce pathogen risk to bumblebees. J. Invertebr. Pathol. 136, 68-73.

Hansen, H., Brødsgaard, C.J., 1999. American foulbrood: a review of its biology, diagnosis and control. Bee World. 80, 5-23.

Haseman, L., 1961. How long can spores of American foulbrood live. Am. Bee J. 101, 298-299.

Higes, M., et al., 2010. Nosema ceranae in Europe: an emergent type C nosemosis. Apidologie 41, 375-392.

Hornitzky, M.A.Z., 1994. Commercial use of gamma radiation in the beekeeping industry. Bee World 75, 135-142.

Hou, Y., et al., 2010. Serious overestimation in quantitative PCR by circular (supercoiled) plasmid standard: microalgal pcna as the model gene. PLoS ONE 5, e9545.

Huang, S.K., et al., 2014. Evaluation of cage designs and feeding regimes for honey bee (Hymenoptera: Apidae) laboratory experiments. J. Econ. Entomol. 107, 54-62.

Huang, W.-F., et al., 2013. Nosema ceranae escapes fumagillin control in honey bees. PLoS Pathog. 9, e1003185.

Hume, A., et al., 2016. Inactivation of RNA viruses by gamma irradiation: a study on mitigating factors. Viruses 8, 204.

Hunter, W., et al., 2010. Large-scale field application of RNAi technology reducing Israeli Acute Paralysis Virus disease in honey bees (Apis mellifera, Hymenoptera: Apidae). PLoS Pathog. 6, e1001160.

ISO\#13409, 2002. Sterilization of health care products: radiation sterilization-substantiation of $25 \mathrm{kGy}$ as a sterilization dose for small or infrequent production batches. In: Organization, I.S. (Ed.), Geneva, Switzerland.

James, R.R., 2011. Potential of ozone as a fumigant to control pests in honey bee (Hymenoptera: Apidae) hives. J. Econ. Entomol. 104, 353-359.
Klee, J., et al., 2007. Widespread dispersal of the microsporidian Nosema ceranae, an emergent pathogen of the western honey bee, Apis mellifera. J. Invertebr. Pathol. 96, $1-10$.

Linksvayer, T.A., et al., 2011. Larval and nurse worker control of developmental plasticity and the evolution of honey bee queen-worker dimorphism. J. Evol. Biol. 24, 1939-1948.

Liu, T.P., et al., 1990. The effects of low doses of gamma irradiation on the ultrastructure of Nosema apis in vitro. J. Apic. Res. 29, 165-171.

Maori, E., et al., 2009. IAPV, a bee-affecting virus associated with Colony Collapse Disorder can be silenced by dsRNA ingestion. Insect Mol. Biol. 18, 55-60.

Meeus, I., et al., 2014. Gamma irradiation of pollen and eradication of Israeli acute paralysis virus. J. Invertebr. Pathol. 121, 74-77.

Pankiw, P., et al., 1970. Disinfection of honeybee combs by gamma irradiation. II. European foul brood disease. J. Apic. Res. 9, 165-168.

Pettis, J.S., et al., 2007. Colony collapse disorder working group pathogen sub-group progress report. Am. Bee. J. 147, 595-597.

Priehn, M., et al., 2016. Sterilization of beehive material with a double inductively coupled low pressure plasma. J. Phys. D Appl. Phys. 49, 374002.

Ribière, M., et al., 2010. Chronic bee paralysis: a disease and a virus like no other? J. Invertebr. Pathol. 103, S120-S131.

Sommers, C.H., 2012. Microbial decontamination of food by irradiation. Microbial Decontamination in the Food Industry. Woodhead Publishing, pp. 322-343.

Sullivan, R., et al., 1971. Inactivation of thirty viruses by gamma radiation. Appl. Microbiol. 22, 61-65.

Thomas, F.C., et al., 1981. Gamma ray inactivation of some animal viruses. Can. J. Comp. Med. 45, 397-399.

Traynor, K.S., et al., 2016. Multiyear survey targeting disease incidence in US honey bees. Apidologie 47, 325-347.

vanEngelsdorp, D., et al., 2009a. "Entombed Pollen": a new condition in honey bee colonies associated with increased risk of colony mortality. J. Invertebr. Pathol. 101, 147-149.

vanEngelsdorp, D., et al., 2009b. Colony collapse disorder: a descriptive study. Plos One. 4.

vanEngelsdorp, D., Meixner, M.D., 2010. A historical review of managed honey bee populations in Europe and the United States and the factors that may affect them. J. Invertebr. Pathol. 103 (Suppl.), S80-S95.

Williams, G.R., et al., 2008. Does fumagillin control the recently detected invasive parasite Nosema ceranae in western honey bees (Apis mellifera). J. Invertebr. Pathol. 99, 342-344. 